\title{
Migration and invasion in B16-F10 mouse melanoma cells are regulated by Nrf2 inhibition during treatment with ionizing radiation
}

\author{
YALI GAO $^{1 *}$, ZISHEN ZHAO ${ }^{2 *}$, XIAOYIN MENG ${ }^{3}$, HONGGUAG CHEN ${ }^{4}$ and GUOJUN FU ${ }^{2}$ \\ ${ }^{1}$ Department of Radiotherapy, Cangzhou Central Hospital, Cangzhou, Hebei 061001; \\ ${ }^{2}$ Department of Dermatology, Cangzhou City People's Hospital, Cangzhou, Hebei 061000; \\ ${ }^{3}$ Department of Gynaecology and Obstetrics, Tianjin Hospital, Tianjin 300211; ${ }^{4}$ Department of Anesthesiology, \\ Tianjin Institute of Anesthesiology, General Hospital of Tianjin Medical University, Tianjin 300052, P.R. China
}

Received February 2, 2017; Accepted January 16, 2018

DOI: $10.3892 / \mathrm{ol} .2018 .8799$

\begin{abstract}
Nuclear factor erythroid 2-related factor 2 (Nrf2) serves a critical role in carcinogenesis. The present study examined the effect of $\mathrm{Nrf} 2$ on the proliferation and invasion of melanoma cells that were treated with ionizing radiation. B16-F10 mouse melanoma cells were exposed to various doses of ionizing radiation for different time periods. Small interfering (si)RNAs targeting Nrf2 were transfected into B16-F10 cells, and cell proliferation, invasion and apoptosis were detected by Transwell, MTT or western blot assays. The expression of Nrf2 and its downstream heme oxygenase 1 (HO-1) was analyzed by reverse transcription-quantitative polymerase chain reaction (RT-qPCR) and western blotting. HO-1 activity was also examined. Ionizing radiation stimulated $\mathrm{Nrf} 2$ expression, increased caspase- 3 expression, and reduced the viability, migration and invasion of B16-F10 mouse melanoma cells. Transfection with Nrf2 siRNA was able to inhibit Nrf2 and HO-1 expression in B16-F10 mouse melanoma cells that were treated by ionizing radiation. Inhibition of Nrf2 further reduced cell viability, invasion and migration, and elevated caspase-3 expression in B16-F10 mice melanoma cells that were treated by ionizing radiation. In summary, treatment with ionizing radiation was able to stimulate Nrf2 expression and regulate cell viability, invasion and migration of B16-F10 cells. A combination of Nrf2 knockdown and ionizing radiation treatment exerted a synergistic effect on migration, invasion and apoptosis in B16-F10 murine melanoma cells.
\end{abstract}

Correspondence to: Dr Yali Gao, Department of Radiotherapy, Cangzhou Central Hospital, 16 Xinhua West Road, Xinhua, Cangzhou, Hebei 061001, P.R. China

E-mail: kafeilideshuixian100@126.com

${ }^{*}$ Contributed equally

Key words: NF-E2-related factor 2, melanoma, radiotherapy, invasion, migration

\section{Introduction}

Melanoma, a lethal form of skin cancer, is an aggressive malignancy derived from melanocytes. The incidence rate of melanoma has doubled in the last two decades, and the mortality rate is $\sim 10 \%$ (1). Although melanoma represents only $4 \%$ of skin cancer cases per year, it accounts for $74 \%$ of skin cancer mortalities (2). The characteristics of melanoma include high rates of invasion and metastasis, and it is difficult to treat. The early detection of malignant melanoma is closely associated with survival rates of $\leq 90 \%$. However, detection at late stages of the disease is associated with survival rates of only $10 \%$ (3).

To date, there is no effective clinical treatment for malignant melanoma as the mechanism underlying melanoma development is unclear. Due to its propensity to metastasize, early-stage melanoma is readily treatable but advanced metastatic melanoma develops resistance to treatment (4). Consequently, available chemotherapeutic approaches for melanoma often result in tolerance, a low response rate (5) and high toxicity $(6,7)$. Radiotherapy is currently the one of the best and effective treatments for melanoma. However, the acquisition of radioresistance results in limited application of radiotherapy in tumor tissue.

The transcriptional regulation of cytoprotective genes serves a crucial role in the cellular defense against injury by nuclear factor erythroid 2-related factor 2 (Nrf2) signaling pathway in skin cells (8). Under normal physiological conditions, the Nrf2-encoding gene is constitutively expressed and forms an inactive complex by binding with its negative regulator Kelch Like ECH Associated Protein 1 (Keap1) in the cytoplasm. Following endogenous or exogenous stress stimulation, Nrf2 dissociates from Keap1 and translocates from the cytoplasm into the nucleus and then binds to the antioxidant response element (ARE) located in the nucleus $(9,10)$. The ARE is a cis-acting regulatory element that contributes to the transcription and translation of downstream phase II antioxidant enzymes, including $\mathrm{NAD}(\mathrm{P}) \mathrm{H}$ quinine oxidoreductase 1, glutamate-cysteine ligase catalytic subunit and glutamate-cysteine ligase modifier subunit (11). The 
mutations that lead to the loss and gain of Keap1 and Nrf2 function are responsible for the overexpression of Nrf2, which were detected in various types of cancer cells, including lung, esophageal and skin cancer (12-14). In previous studies, the activation of Nrf2 was associated with the resistance of cancer cells to radiation therapy (15), and Nrf2 regulated radiation-induced apoptosis via the Notch signaling pathway (16).

However, whether the Nrf2/heme oxygenase 1 (HO-1) signaling pathway is responsible for regulating changes in radiation-induced cell proliferation and invasion remains to be clarified. Therefore, the present study focused on the mechanism of Nrf2/HO-1 in radiation-stimulated melanoma cells.

\section{Materials and methods}

Cell culture. B16-F10 melanoma cells were purchased from the American Type Culture Collection (Manassas, VA, USA). The cells were cultured in RPMI-1640 medium (Thermo Fisher Scientific, Inc., Waltham, MA, USA) supplemented with $10 \%$ fetal calf serum (Thermo Fisher Scientific, Inc.), $100 \mathrm{U} / \mathrm{ml}$ penicillin and $100 \mathrm{mg} / \mathrm{ml}$ streptomycin in a humidified atmosphere with $5 \% \mathrm{CO}_{2}$ at $37^{\circ} \mathrm{C}$. Confluent cells were used for the experiments between the 4th and 6th passages. The cells were seeded at a density of $1 \times 10^{6}$ cells $/ \mathrm{ml}$.

Ionizing radiation treatment. Monolayer cells were exposed to ionizing radiation at $37^{\circ} \mathrm{C}$ with a 6-MV X-ray beam produced by a radiotherapy Mark I irradiator (JLS\&A, San Fernando, CA, USA) at acute doses of 2, 4, 8, and 16 Gy with a dose rate of $200 \mathrm{cGy} / \mathrm{min}$ or were sham irradiated as a control. Following irradiation, the cells were cultured at room temperature for $2,4,6,12,24$ and $48 \mathrm{~h}$.

Transfection with small interfering RNA (siRNA) against Nrf2. Nrf2 siRNAs were purchased from Santa Cruz Biotechnology Inc., (Dallas, TX, USA), NRF2-siRNA, 5'-UGAAAGCAC AGCAGAAUUTT-3' and control-siRNA, 5'-GAGCGGCCG AGCAACGUCUAU-3'. According to the manufacturer's protocol, the siRNAs (final siRNA concentration, $10 \mathrm{nM}$ ) were transfected into B16-F10 cells by using the Lipofectamine ${ }^{\circledR}$ RNAiMAX transfection reagent (Invitrogen; Thermo Fisher Scientific Inc., Waltham, MA, USA). The cells were seeded in 6 -well culture plates and incubated with Nrf2 siRNA at $50 \mathrm{nM}$ for $6 \mathrm{~h}$ in serum-free OPTI-MEM media (Invitrogen; Thermo Fisher Scientific Inc.). Following incubation for $24 \mathrm{~h}$ at $37^{\circ} \mathrm{C}$, the transfected cells were used for subsequent experiments.

Reverse transcription-quantitative polymerase chain reaction $(R T-q P C R)$. The cells were harvested to detect mRNA by RT-qPCR. Total RNA was extracted from cultured cells by using TRIzol ${ }^{\circledR}$ reagent (Life Technologies; Thermo Fisher Scientific Inc.) according to the manufacturer's protocol, and reverse transcription was performed using a PrimeScript RT Master Mix (Takara Biotech Co., Ltd., Dalian, China) in a total volume of $20 \mu \mathrm{l}$ followed by 30 cycles of $94^{\circ} \mathrm{C}$ for $20 \mathrm{sec}$, $55^{\circ} \mathrm{C}$ for $20 \mathrm{sec}$ and $70^{\circ} \mathrm{C}$ for $40 \mathrm{sec}$; then final extension at $70^{\circ} \mathrm{C}$ for $5 \mathrm{~min}$. The primers were designed and synthesized by Hanghai Sangon Biological Engineering Technology \& Services (Shanghai, China). The following primers were used for the PCR experiments: Nrf2 forward, 5'-AGCCCA GCACATCCAGTCA-3' and reverse, 5'-TGCATGCAGTCA TCAAAGTACAAAG-3'; and $\beta$-actin forward, 5'-TGGCAC CCAGCACAATGAA-3' and reverse, 5'-CTAAGTCATAGT CCGCCTAGAAGCA-3'. SYBR-Green Master Mix (Applied Biosystems; Thermo Fisher Scientific, Inc.) was used for RT-qPCR to determine the relative levels of target mRNA. The reaction was conducted on an FTC-3000 qPCR system (Shanghai Funglyn Biotech Co., Ltd. Shanghai, China), in the following thermocycling conditions: $94^{\circ} \mathrm{C}$ for $30 \mathrm{sec}, 59^{\circ} \mathrm{C}$ for $30 \mathrm{sec}$ and $72^{\circ} \mathrm{C}$ for $45 \mathrm{sec}$, for 40 cycles. The experiment was repeated 3 times. Relative expression levels of Nrf2 were calculated according to $\beta$-actin (17).

Western blot analysis. The cells were collected to analyze the expression of Nrf2 and HO-1. The cells were washed with cold PBS and lysed at $4^{\circ} \mathrm{C}$ with RIPA buffer (Beyotime Institute of Biotechnology, Haimen, China) and harvested for $30 \mathrm{~min}$ on ice. Following centrifugation at $10,000 \times \mathrm{g}$ for $20 \mathrm{~min}$ at $4^{\circ} \mathrm{C}$, the supernatant was used as total cell lysate. The total protein concentrations were determined using a Pierce BCA protein assay kit (Thermo Fisher Scientific Inc.) according to the manufacturer's protocol. A total of $20 \mu \mathrm{g}$ of protein were separated onto $12 \%$ SDS-PAGE, and the proteins were then transferred electrophoretically onto polyvinylidene fluoride membranes (Roche Diagnostics, Basel, Switzerland). The membranes were blocked with blocking solution $[0.05 \%$ Tween and $5 \%$ bovine serum albumin (BSA; BBI Life Sciences Corp., Shanghai, China)] in Tris-buffered saline for $2 \mathrm{~h}$ at room temperature and incubated with primary rabbit monoclonal antibodies against Nrf2 (cat. no. ab62352; 1:500), primary mouse monoclonal antibodies against HO-1 (cat. no. ab13248; 1:500), primary rabbit polyclonal antibodies against cleaved caspase-3 (cat. no. ab2302; 1:500), or primary mouse monoclonal antibodies against $\beta$-actin (cat. no. ab8226; 1:1,000; all Abcam, Cambridge UK), overnight at $4^{\circ} \mathrm{C}$. The membranes were incubated with horseradish peroxidase-conjugated secondary antibodies against Nrf2, HO-1, cleaved caspase-3 and $\beta$-actin (anti-mouse IgG; dilution, 1:10,000; cat. no. ab97046; anti-rabbit IgG; dilution, 1:10,000; cat. no. ab7090; Abcam) at room temperature for $1 \mathrm{~h}$, which were detected using an enhanced chemiluminescence detection system (Amersham; GE Healthcare, Chicago, IL, USA). The intensity of the bands was analyzed using Image J software version 1.4.6 (National Institutes of Health, Bethesda, MD, USA).

Cell viability. The viability of the cells was assessed by MTT assay. The cells were seeded in a 96-well plate overnight. The cells were treated with ionizing radiation and/or siRNA according to the manufacturer's protocol. Subsequently, MTT solution was added to each well and incubated for an additional $3 \mathrm{~h}$ at $37^{\circ} \mathrm{C}$. The media was discarded, and dimethyl sulfoxide was added to each well to dissolve the formazan crystals. Absorbance at $540 \mathrm{~nm}$ was measured using a microplate reader (EL-808; BioTek Instruments, Inc., Winooski, VT, USA). The $\mathrm{OD}$ values of the $0 \mathrm{~h}$ or $\mathrm{BF}$ groups were used as the controls.

HO- 1 activity. HO-1 activity was determined at $12 \mathrm{~h}$ after treatment with siRNA and ionizing radiation stimulation. As described in a previous study (18), the cells were collected by 
A

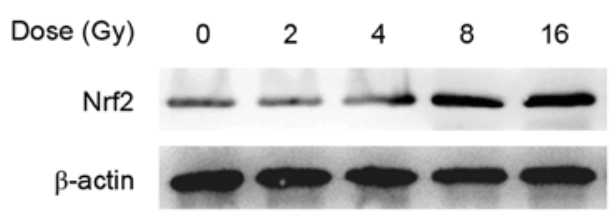

B

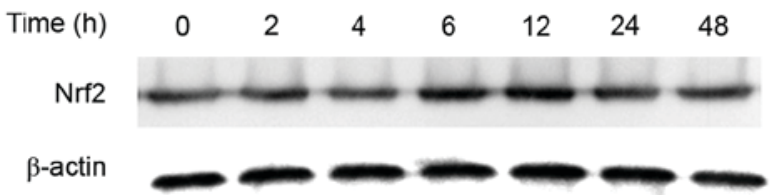

C

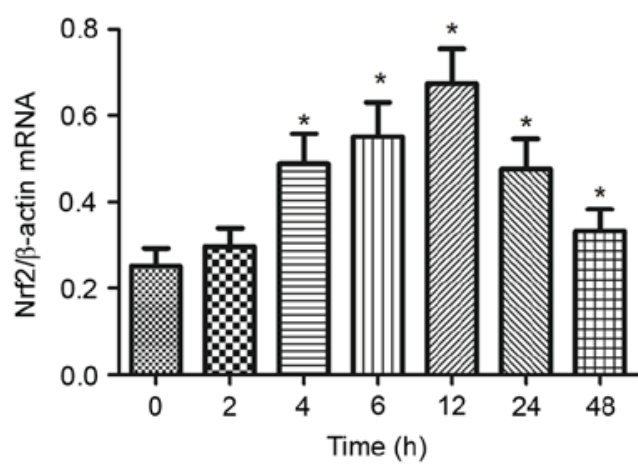

Figure 1. Effect of ionizing radiation on Nrf2 expression in B16-F10 melanoma cells. (A) B16-F10 melanoma cells were treated with various doses of ionizing radiation at $12 \mathrm{~h}$. A single dose of $8 \mathrm{~Gy}$ was used to radiate B16-F10 melanoma at different time points. The cells were harvested to investigate the expression of (B) Nrf2 protein and (C) mRNA. All data are expressed as the mean \pm standard deviation. * $\mathrm{P}<0.05$ vs. 0 Gy; $\mathrm{n}=6$. Nrf2, nuclear factor erythroid 2-related factor 2 .

centrifugation for $25 \mathrm{~min}$ at $10,000 \mathrm{x}$ g at $4^{\circ} \mathrm{C}$. The activity of the HO-1 enzyme was detected in a reaction mixture containing microsomes, a cytosolic fraction of rat liver (a source of biliverdin reductase) hemin and NADPH (18). The reaction mixture was incubated at $37^{\circ} \mathrm{C}$ for $1 \mathrm{~h}$ in the dark, and the bilirubin was extracted with $1 \mathrm{ml}$ chloroform by vigorous vortexing three times for $10 \mathrm{sec}$. The amount of extracted bilirubin was measured at 464 and $530 \mathrm{~nm}$ of organic phase. HO-1 activity was represented as pmol bilirubin $/ \mathrm{mg}$ protein $/ \mathrm{h}$.

Cell migration. The B16-F10 cell migration assay was performed using a commercial Transwell insert (8- $\mu \mathrm{m}$ pore size; Corning Incorporated, Corning, NY, USA). The migratory potential of the cells was assessed at $24 \mathrm{~h}$ post-siRNA transfection, at $0,2,4,6,12$ and $24 \mathrm{~h}$ after ionizing radiation in media containing $10 \%$ fetal bovine serum (FBS; Thermo Fisher Scientific, Inc.), followed by serum starvation for an additional $24 \mathrm{~h}$. Then, $2 \times 10^{5}$ serum-starved cells were seeded in the upper chamber of the Transwell insert (cat. no. PIEP15R48; EMD Millipore, Billerica, MA, USA). Dulbecco's modified Eagle's medium (Thermo Fisher Scientific, Inc.) containing 10\% FBS was added to the lower chamber as a chemoattractant. The non-invading cells were removed from the upper surface of the membrane in different groups after $24 \mathrm{~h}$. The migrated cells on the underside of the filter were first fixed with $100 \%$ methanol and then stained by $0.1 \%$ crystal violet solution for $10 \mathrm{~min}$ at room temperature. The cells were counted in five random fields under an inverted microscope at magnification, $x 40$. The data were calculated and expressed as fold increase vs. control groups.

Cell invasion. Cell invasive ability was assessed using Matrigel invasion chambers (BD Biosciences, Franklin Lakes, NJ, USA). The invasive ability of the cells were detected at $24 \mathrm{~h}$ post-siRNA transfection at $0,2,4,6,12$ and $24 \mathrm{~h}$ after ionizing radiation, in media containing $10 \%$ FBS followed by serum starvation for an additional $12 \mathrm{~h}$. Then, $1 \times 10^{5}$ cells in serum-free medium containing $10 \%$ BSA were added to the upper chamber, while serum-containing medium with $10 \%$ FBS was placed in the lower chamber. After $24 \mathrm{~h}$, the cells on the surface of the upper membrane were removed. The cells that penetrated the insert and migrated to the bottom chamber were stained with $0.1 \%$ crystal violet solution for $10 \mathrm{~min}$ at room temperature and counted as previously described for the cell migration assay.

Statistical analysis. The data are presented as the mean \pm standard deviation. One-way analysis of variance was used to determine significant differences among all groups followed by Fisher's least significant difference comparison. $\mathrm{P}<0.05$ was considered to indicate a statistically significant difference.

\section{Results}

Ionizing radiation stimulates Nrf2 expression in B16-F10 mouse melanoma cells. Nrf2 serves an important role in a number of skin-associated diseases (19) and also protects melanocytes against harmful oxidative stress (20). Previously, studies have reported that $\mathrm{Nrf} 2$ is induced by a variety of stimuli, including ionizing radiation, in bone tissue and lung cancer cells $(16,21)$. To clarify whether variations in Nrf2 expression are involved in ionizing radiation-induced melanoma development, the effect of ionizing radiation on $\mathrm{Nrf} 2$ expression was examined in the present study. Following the treatment of different doses of ionizing radiation (1-16 Gy) and for various time periods ( $0-48 \mathrm{~h}), \mathrm{Nrf} 2$ protein expression was investigated by western blot analysis. The results indicated that Nrf2 expression was induced in a dose-dependent manner with peak expression induced by 8 Gy (Fig. 1A). Nrf2 expression was gradually increased from 0-48 h following exposure to $8 \mathrm{~Gy}$ ionizing radiation with peak expression at $12 \mathrm{~h}$ (Fig. 1B and C). The changes in Nrf2 mRNA expression in B16-F10 melanoma cells were similar to the pattern of Nrf2 protein expression following exposure to ionizing radiation.

Effect of ionizing radiation on the viability and apoptosis of B16-F10 mouse melanoma cells. Following the analysis of the results in Fig. 1, 8 Gy was selected to radiate the melanoma cells in subsequent experiments. To investigate the viability of B16-F10 cells following ionizing radiation, cell viability and the levels of cleaved caspase- 3 following the exposure to 8 Gy 
ionizing radiation at 0-24 $\mathrm{h}$ were analyzed by MTT assay and western blotting, respectively. The results of the cell viability assay indicated a significant decrease in the number of living cells from 2 to $24 \mathrm{~h}$ compared with $0 \mathrm{~h}$, in a time-dependent manner (Fig. 2A). Caspase-3 is crucial mediator of apoptosis. Over the duration of the experiment $(24 \mathrm{~h})$, the expression of cleaved caspase-3 was increasingly elevated following exposure to 8 Gy ionizing radiation (Fig. 2B and C).

Ionizing radiation inhibits the migration and invasion of melanoma cells. Cell migration and invasion serve an important role in cancer metastasis. In the present study, the effect of ionizing radiation on the migration and invasion of melanoma cells was investigated by Transwell chamber and Matrigel invasion assays. The results indicated that the invasive and migratory abilities of B16-F10 cells were inhibited by 8 Gy ionizing radiation compared with the $0 \mathrm{~h}$ group (Fig. 3A). The results also indicated that exposure to $8 \mathrm{~Gy}$ ionizing radiation inhibited the migration of B16-F10 cells in a time-dependent manner compared with 0 h group (Fig. 3B).

Transfection of Nrf2 siRNA decreases Nrf2 expression and downstream HO-1 following ionizing radiation in melanoma cells. To discuss the role of Nrf2 in melanoma cells following exposure to ionizing radiation, Nrf2 siRNA was utilized to inhibit Nrf2 expression in the present study. The results identified that transfection with Nrf2 siRNA was able to inhibit the expression of $\mathrm{Nrf} 2$ protein and mRNA compared with untreated B16-F10 cells (Fig. 4). Furthermore, the combined treatment with Nrf2 siRNA and ionizing radiation significantly inhibited the expression of Nrf2 protein and mRNA in the B16-F10 + IR + siRNA group compared with the B16-F10 + IR group (Fig. 4). To further examine the effect of Nrf2 on its downstream target gene, HO-1, mRNA levels were detected following exposure to IR. Notably, the patterns of HO-1 mRNA expression and changes in the activity of HO-1 were similar to Nrf2 in the four treatment groups (Fig. 4C-F).

Effect of Nrf2 on cell viability and the activity of caspase-3 in irradiated B16-F10 cells. Cell viability was analyzed by MTT assay. Compared with the B16-F10 + IR group or B16-F10 + siRNA group, combined treatment with Nrf2 siRNA and ionizing radiation markedly inhibited cell viability in the B16-F10 + IR + siRNA group (Fig. 5A). A combination of exposure to ionizing radiation and siRNA-induced Nrf2 inhibition increased the cleaved caspase- 3 expression compared with the untreated B16-F10 group (Fig. 5B). Compared with the B16-F10 + IR group or B16-F10 + siRNA group, treatment with Nrf2 siRNA and ionizing radiation further elevated cleaved caspase-3 expression in the B16-F10 + IR + siRNA group (Fig. 5B). These results indicated that treatment with ionizing radiation may inhibit cell viability and promote apoptosis via Nrf2 expression in B16-F10 cells.

Inhibition of Nrf2 reduces the migration and invasion of B16-F10 cells that are exposed to ionizing radiation. Compared with the untreated B16-F10 cells, migration and invasion were inhibited in the B16-F10 + IR and B16-F10 + siRNA groups (Fig. 5C and D). Furthermore, combined treatment with Nrf2 siRNA and ionizing radiation
A

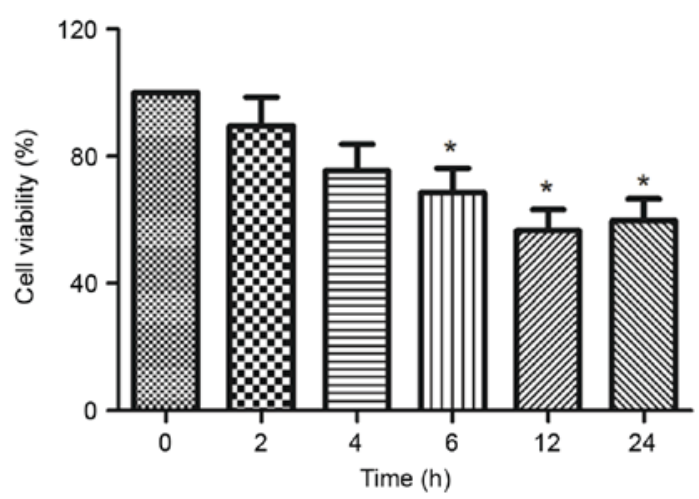

B

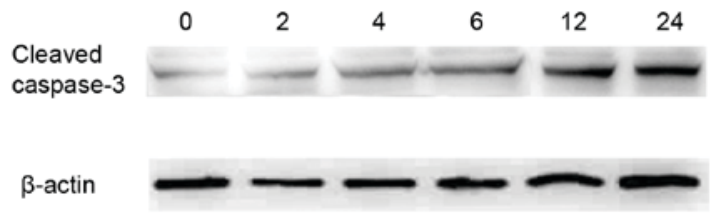

C

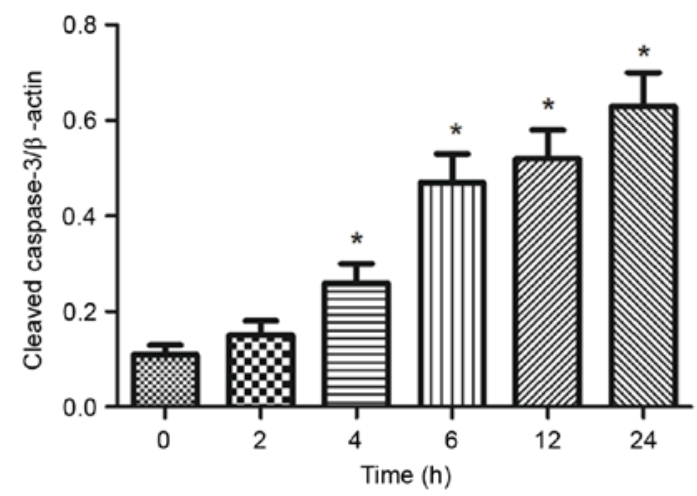

Figure 2. Exposure to ionizing radiation induces changes in cell viability and apoptosis in B16-F10 melanoma cells. B16-F10 melanoma cells were induced by $8 \mathrm{~Gy}$ ionizing radiation for different time points. The cells were collected, and (A) cell viability was analyzed using MTT assay. (B) The expression of cleaved caspase-3 was analyzed by western blotting. (C) Quantitative analysis of western blotting results. All data are expressed as the mean \pm standard deviation. ${ }^{*} \mathrm{P}<0.05$ vs. $0 \mathrm{~h} ; \mathrm{n}=6$.

significantly inhibited migration and invasion compared with the B16-F10 + IR or B16-F10 + siRNA groups (Fig. 5D). These results demonstrated that ionizing radiation may inhibit the migration and invasion of B16-F10 cells via Nrf2 expression.

\section{Discussion}

The aim of the present study was to elucidate the mechanisms and role of Nrf2 in the apoptosis, migration and invasion of radiated melanoma cells. The results indicated that ionizing radiation stimulated the expression of Nrf2 in B16-F10 melanoma cells. Furthermore, ionizing radiation decreased the cell viability and increased cell apoptosis, while also inhibiting the migration and invasion of melanoma cells. Transfection with Nrf2 siRNA decreased the expression and activity of Nrf2 and the expression and activity of its downstream target, 
A

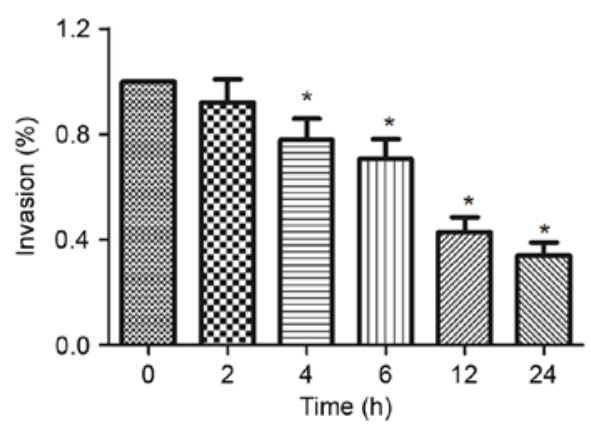

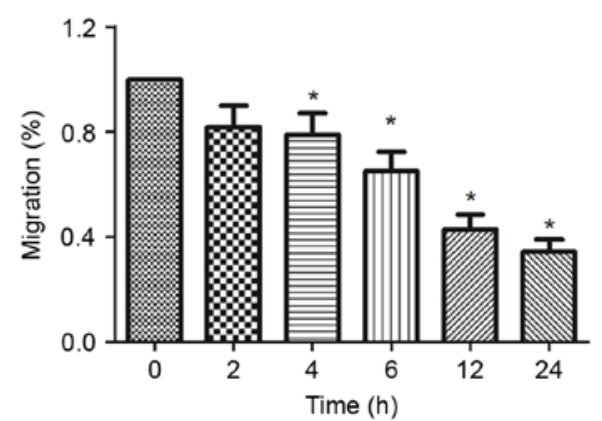

Figure 3. Effect of ionizing radiation on the invasion and migration of B16-F10 melanoma cells. B16-F10 melanoma cells were induced by 8 Gy ionizing radiation at different time points. (A) The cells were collected to detect cell invasion and (B) migration. All data are expressed as the mean \pm standard deviation. ${ }^{*} \mathrm{P}<0.05$ vs. $0 \mathrm{~h} ; \mathrm{n}=6$.

A

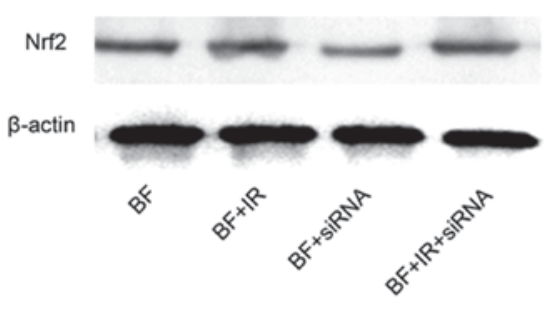

C

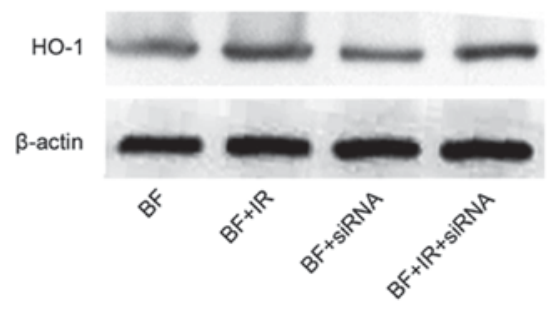

E

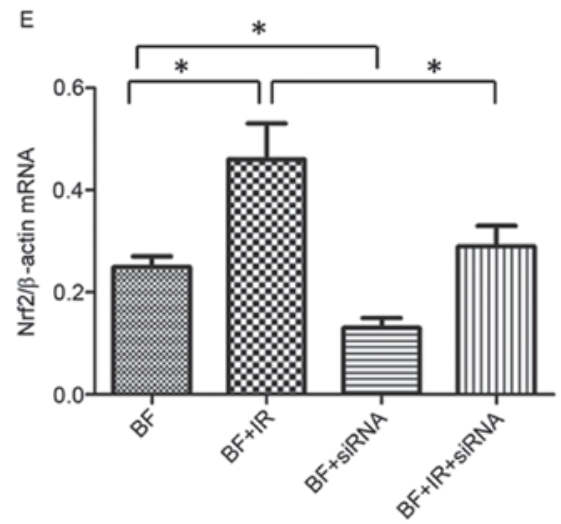

B

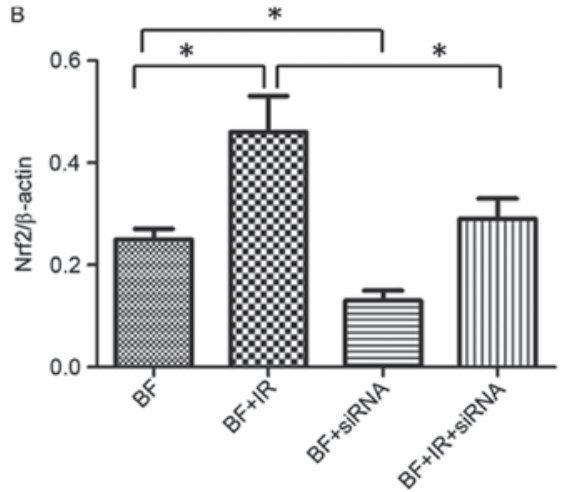

D
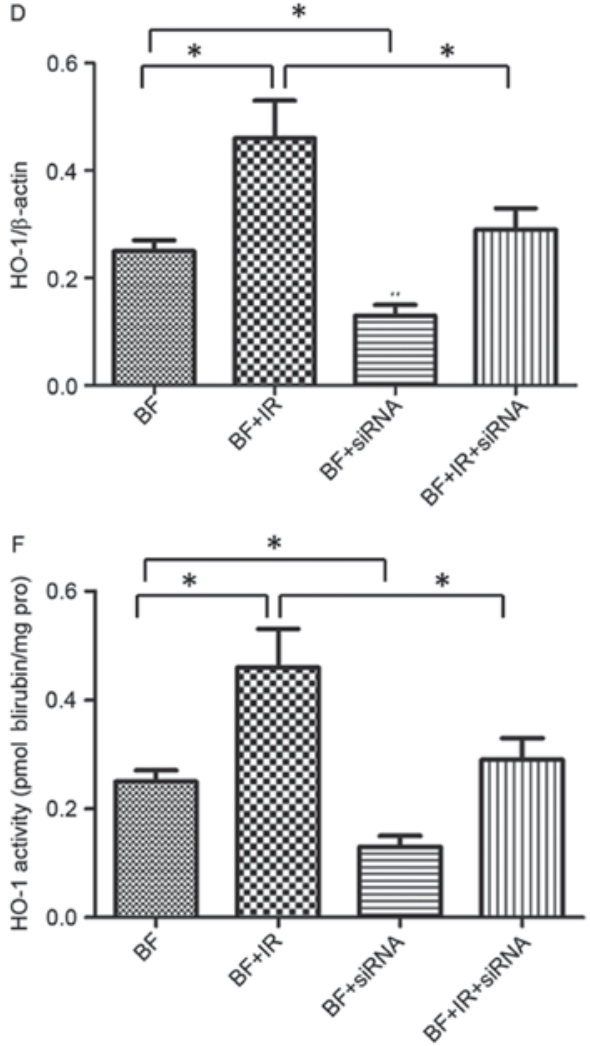

Figure 4. Effect of Nrf2 knockdown on Nrf2 and HO-1 in B16-F10 melanoma cells that were induced by ionizing radiation. B16-F10 melanoma cells were radiated by a dose of $8 \mathrm{~Gy}$ for $12 \mathrm{~h}$ following the treatment of melanoma cells with Nrf 2 siRNA. The cells were harvested and western blotting was performed to detect the expression of (A) Nrf2 protein. (B) Quantitative analysis of Nrf2 protein expression. (C) Western blot analysis of HO-1 protein expression. (D) Quantitative analysis of HO-1 protein expression. (E) Reverse transcription-quantitative polymerase chain reaction of Nrf2 mRNA. (F) Analysis of HO-1 activity. All data are expressed as the mean \pm standard deviation ${ }^{*} \mathrm{P}<0.05$. $\mathrm{n}=6$. BF, B16-F10 cells; HO-1, heme oxygenase 1 ; IR, Ionizing radiation; Nrf2, nuclear factor erythroid 2-related factor 2; siRNA, small-interfering RNA. 


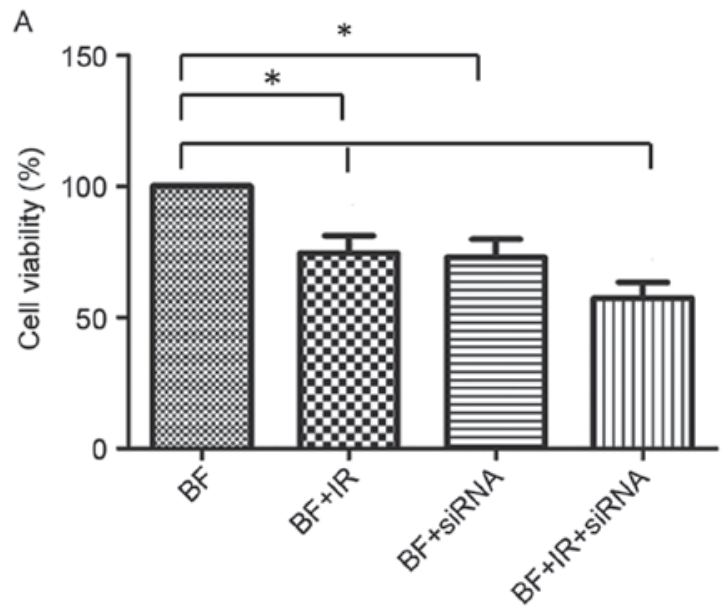

B Cleaved caspase-3
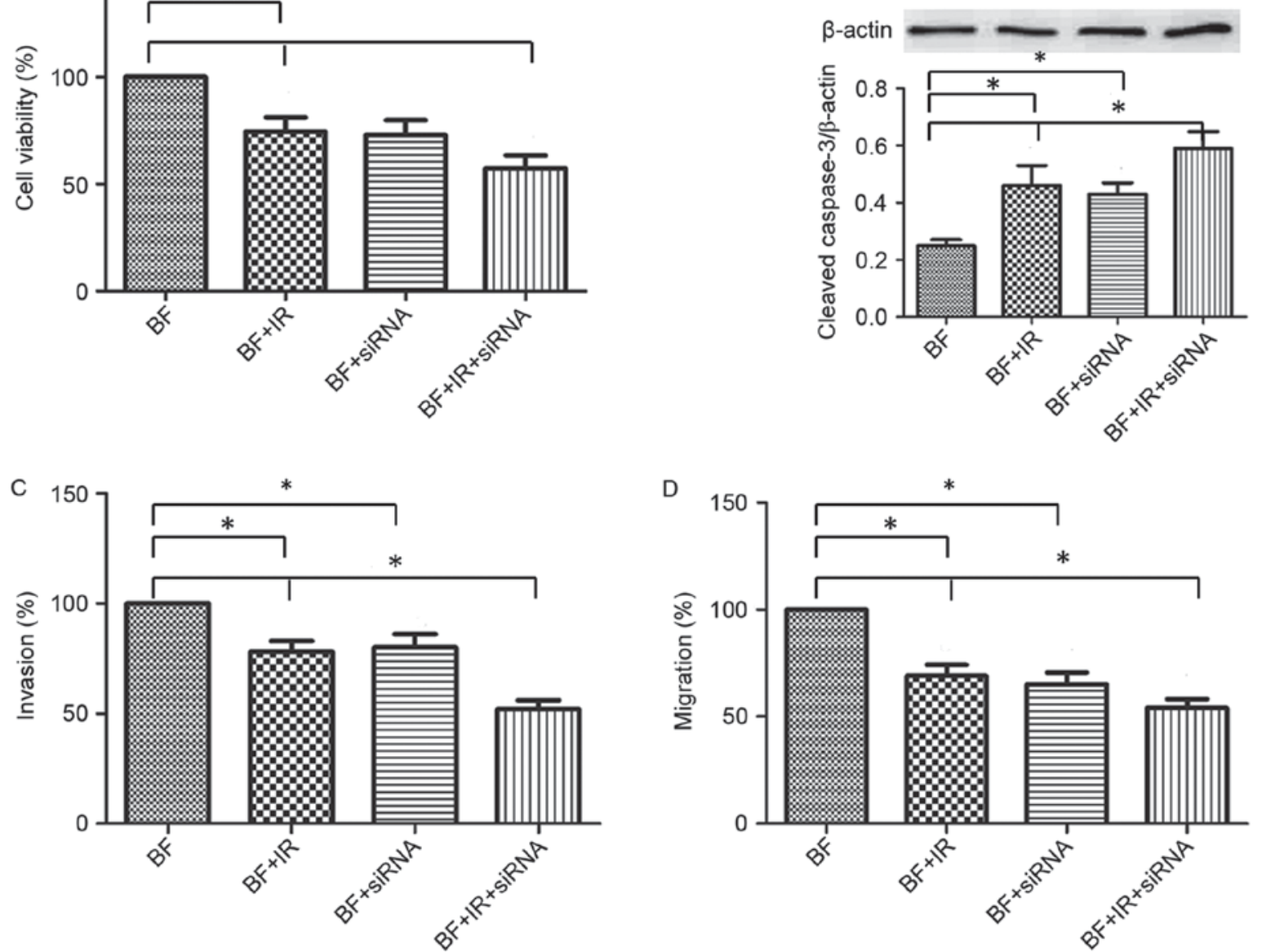

Figure 5. Effect of Nrf2 knockdown on the viability, caspase-3 expression, invasion and migration of B16-F10 melanoma cells that were induced by ionizing radiation. B16-F10 melanoma cells were radiated by a dose of $8 \mathrm{~Gy}$ for $12 \mathrm{~h}$ following the treatment of melanoma cells with Nrf2 siRNA. The cells were harvested. Subsequently, (A) cell viability, (B) cleaved caspase-3 expression, (C) invasive and (D) migratory capacities were assessed. All data are expressed as the mean \pm standard deviation " $\mathrm{P}<0.05 ; \mathrm{n}=6$. BF, B16-F10 cells; IR, Ionizing radiation; Nrf2, nuclear factor erythroid 2-related factor 2; siRNA, small-interfering RNA.

HO-1. Ionizing radiation may exhibit a regulatory effect on the apoptosis, migration and invasion via activation of the Nrf2 signaling pathway in B16-F10 melanoma cells.

Metastasis is a primary cause of cancer-associated mortalities, which accounts for $>90 \%$, and includes a multi-step process of cell adhesion, migration and invasion (22). Inhibiting the metastasis of cancer cells is a principal strategy for cancer therapy and research (23). Melanoma, a type of skin tumor, generally has a poor prognosis due to its invasive behavior. The treatments for melanoma include surgery, radiotherapy and chemotherapy (24). Particularly for advanced malignant melanoma, there is currently no effective and safe treatment. In the present research, it was identified that exposure to $8 \mathrm{~Gy}$ radiation decreased cell viability and increased the cleaved caspase-3 expression in B16-F10 melanoma cells. Additional experiments verified that radiotherapy exerted an inhibitory effect on the migration and invasion of melanoma cells. These results indicated that radiotherapy exerts an inhibitory effect on cancer metastasis, and therefore it has the potential to improve the survival period of patients with melanoma.

Although Nrf2 exhibits a beneficial effect in liver ischemia-reperfusion (25) and macrophage inflammatory response (26), the effect of Nrf2 on melanoma is currently unknown. Previous studies have suggested that Nrf2 functions as an oncogene in tumor progression, and it is regarded as a pro-tumorigenic factor in a number of tumor types by accelerating stress adaption, increasing drug resistance and promoting oncogenesis (27). Types of cancer that are often in a continuous state of oxidative stress appear to have a constitutively activated Nrf2-ARE pathway, resulting in enhanced tumor cell survival (28). In response to external stimuli, a series of events leads to the stabilization of Nrf2 and its translocation into the nucleus, where Nrf2 exerts its function and controls the expression of antioxidants (29). In the present study, various doses of ionizing radiation doses were used to investigate the changes in $\mathrm{Nrf} 2$ expression following the treatment of B16-F10 melanoma cells. The results indicated that ionizing radiation stimulated $\mathrm{Nrf} 2$ expression in a dose-dependent manner with the exception of 8 Gy having the same effect on Nrf2 expression as $16 \mathrm{~Gy}$. The effect of 8 Gy on Nrf2 expression following different time periods of exposure to ionizing radiation was also investigated. It was indicated that treatment with $8 \mathrm{~Gy}$ ionizing radiation gradually increased the expression of Nrf2 from 0 to $12 \mathrm{~h}$, and Nrf2 expression was decreased from 12-24 h. Tsukimoto et al (30) reported that $\gamma$-radiation exhibited an 
inducing effect on Nrf2 and that it increased the nuclear accumulation of Nrf2 and HO-1 expression in the murine Raw 264.7 macrophage cell line. These results are consistent with those obtained by the present study. Additionally, it was reported that this highly robust Nrf2-ARE-mediated antioxidant response, which was detected after 5 days, was radiation dose- and time-dependent. The Nrf2-ARE-mediated antioxidant response was also associated with delayed reactive oxygen species (ROS) production as measured by fluorescent ROS-sensitive dyes (13).

To further investigate the effect of Nrf2 in ionizing radiation-treated melanoma cells, Nrf2 expression was inhibited by $\mathrm{Nrf} 2$ siRNA, and the levels of Nrf2 protein and its downstream target were detected. In the present study, treatment with Nrf2 siRNA was demonstrated to markedly inhibit Nrf2 expression. Furthermore, treatment with Nrf2 siRNA reversed the increase in Nrf2 expression that was induced by ionizing radiation compared with untreated melanoma cells.

Furthermore, the expression of HO-1 (a target of Nrf2) and its activity were significantly inhibited by Nrf2 siRNA treatment in melanoma cells. Meng et al (31) reported that Nrf2 and its target protein HO-1 were involved with cell migration and vascular tube formation in human microvascular endothelial cells, and Pan et al (32) identified that Nrf2 exerted a regulatory effect on cell migration and invasion in glioma cells. These results indicated that Nrf2 may participate in the process of cell migration and invasion. Therefore, it was hypothesized that Nrf2 was associated with cell migration and invasion in melanoma cells that were treated with ionizing radiation. The results of the present study revealed that siRNA-induced Nrf2 inhibition decreased the migration and invasion of melanoma cells, and Nrf2 siRNA was able to inhibit the cell viability and augment caspase-3 activity in melanoma cells compared with untreated melanoma cells. These results indicated that ionizing radiation is able to decrease the migration and invasion of melanoma cells and stimulate apoptosis and $\mathrm{Nrf} 2$ expression. The knockdown of Nrf2 exerts a positive role in migration, invasion and apoptosis.

In the present study, radiation stimulated Nrf 2 expression and increased caspase- 3 expression. Furthermore, exposure to radiation reduced cell viability, migration and invasion. Inhibition of Nrf2 expression induced by Nrf2 siRNA also increased caspase-3 expression and reduced cell viability, migration and invasion. Why is there a similar pattern of caspase-3 expression, cell viability, migration and invasion between Nrf2 overexpression and Nrf2 inhibition? Nrf2 exerts dual functions in melanoma (33); radiation treatment increased Nrf2 expression (13). We hypothesize that the radiation treatment did not induce sufficient Nrf2 expression to decrease caspase- 3 expression, cell viability, migration and invasion in the present study; therefore, the effect of radiation was greater than Nrf2's ability to ameliorate its effects.

To conclude, the present study identified the effect of $\mathrm{Nrf} 2 / \mathrm{HO}-1$ on migration, invasion and apoptosis in melanoma cells following ionizing radiation treatment. However the mechanisms by which Nrf2 and its target genes regulate migration and invasion remain to be elucidated. Further research is required in order to investigate the prevention and treatment of melanoma.

\section{Acknowledgements}

Not applicable.

\section{Funding}

No funding was received.

\section{Availability of data and materials}

All data generated or analyzed during this study are included in the published article.

\section{Authors' contributions}

YG and ZZ designed the experiments. YG, XM and GF performed the experiments. YG, ZZ and $\mathrm{HC}$ processed the data and wrote the manuscript. All authors read and approved the final manuscript.

\section{Ethics approval and consent to participate}

Not applicable.

\section{Consent for publication}

Not applicable.

\section{Competing interests}

The authors declare that they have no competing interests.

\section{References}

1. Heideman DA, Lurkin I, Doeleman M, Smit EF, Verheul HM, Meijer GA, Snijders PJ, Thunnissen E and Zwarthoff EC: KRAS and BRAF mutation analysis in routine molecular diagnostics: Comparison of three testing methods on formalin-fixed, paraffin-embedded tumor-derived DNA. J Mol Diagn 14: 247-255, 2012.

2. Kanzler MH and Swetter SM: Malignant melanoma. J Am Acad Dermatol 48: 780-783, 2003.

3. Streicher KL, Zhu W, Lehmann KP, Georgantas RW, Morehouse CA, Brohawn P, Carrasco RA, Xiao Z, Tice DA, Higgs BW, et al: A novel oncogenic role for the miRNA-506-514 cluster in initiating melanocyte transformation and promoting melanoma growth. Oncogene 31: 1558-1570, 2012.

4. Reintgen D, Cruse CW and Atkins M: Cutaneous malignant melanoma. Clin Dermatol 19: 253-261, 2001.

5. Serrone L, Zeuli M, Sega FM and Cognetti F: Dacarbazine-based chemotherapy for metastatic melanoma: Thirty-year experience overview. J Exp Clin Cancer Res 19: 21-34, 2000.

6. Alwan LM, Grossmann K, Sageser D, Van Atta J, Agarwal N and Gilreath JA: Comparison of acute toxicity and mortality after two different dosing regimens of high-dose interleukin-2 for patients with metastatic melanoma. Target Oncol 9: 63-71, 2014.

7. Atkins MB, Lotze MT, Dutcher JP, Fisher RI, Weiss G, Margolin K, Abrams J, Sznol M, Parkinson D, Hawkins M, et al: High-dose recombinant interleukin 2 therapy for patients with metastatic melanoma: Analysis of 270 patients treated between 1985 and 1993. J Clin Oncol 17: 2105-2116, 1999.

8. Li N, Alam J, Venkatesan MI, Eiguren-Fernandez A, Schmitz D, Di Stefano E, Slaughter N, Killeen E, Wang X, Huang A, et al: Nrf2 is a key transcription factor that regulates antioxidant defense in macrophages and epithelial cells: Protecting against the proinflammatory and oxidizing effects of diesel exhaust chemicals. J Immunol 173: 3467-3481, 2004.

9. Bütof R, Dubrovska A and Baumann M: Clinical perspectives of cancer stem cell research in radiation oncology. Radiother Oncol 108: 388-396, 2013 
10. Baird L, Llères D, Swift S and Dinkova-Kostova AT: Regulatory flexibility in the Nrf2-mediated stress response is conferred by conformational cycling of the Keap1-Nrf2 protein complex. Proc Natl Acad Sci USA 110: 15259-15264, 2013.

11. Canning P, Sorrell FJ and Bullock AN: Structural basis of KEAP1 interactions with Nrf2. Free Radic Biol Med 91: 101-107, 2015.

12. Lee S, Lim MJ, Kim MH, Yu CH, Yun YS, Ahn J and Song JY: An effective strategy for increasing the radiosensitivity of human lung cancer cells by blocking Nrf2-dependent antioxidant responses. Free Radic Biol Med 53: 807-816, 2012.

13. Medonald JT, Kim K, Norris AJ, Vlashi E, Phillips TM, Lagadec C, Della Donna L, Ratikan J, Szelag H, Hlatky L and McBride WH: Ionizing radiation activates the Nrf2 antioxidant response. Cancer Res 70: 8886-8895, 2010.

14. Singh A, Bodas M, Wakabayashi N, Bunz F and Biswal S: Gain of Nrf2 function in non-small-cell lung cancer cells confers radioresistance. Antioxid Redox Signal 13: 1627-1637, 2010.

15. Shibata T, Ohta T, Tong KI, Kokubu A, Odogawa R, Tsuta K, Asamura H, Yamamoto M and Hirohashi S: Cancer related mutations in NRF2 impair its recognition by Keap1-Cul3 E3 ligase and promote malignancy. Proc Natl Acad Sci USA 105: 13568-13573, 2008.

16. Zhao Q, Mao A, Yan J, Sun C, Di C, Zhou X, Li H, Guo R and Zhang H: Downregulation of Nrf2 promotes radiation-induced apoptosis through Nrf2 mediated Notch signaling in non-small cell lung cancer cells. Int J Oncol 48: 765-773, 2016.

17. Livak KJ and Schmittgen TD: Analysis of relative gene expression data using real-time quantitative PCR and the 2(-Delta Delta $\mathrm{C}(\mathrm{T})$ ) method. Methods 25: 402-408, 2001.

18. Konrad FM, Zwergel C, Ngamsri KC and Reutershan J: Anti-inflammatory effects of heme oxygenase-1 depend on adenosine A2A- and A2B-receptor signaling in acute pulmonary inflammation. Front Immunol 8: 1874, 2017.

19. Gegotek A and Skrzydlewska E: The role of transcription factor Nrf2 in skin cells metabolism. Arch Dermatol Res 307: 385-396, 2015.

20. Jeayeng S, Wongkajornsilp A, Slominski AT, Jirawatnotai $S$, Sampattavanich S and Panich U: Nrf2 in keratinocytes modulates UVB-induced DNA damage and apoptosis in melanocytes through MAPK signaling. Free Radic Biol Med 108: 918-928, 2017.

21. Rana T, Schultz MA, Freeman ML and Biswas S: Loss of Nrf2 accelerates ionizing radiation-induced bone loss by upregulating RANKL. Free Radic Biol Med 53: 2298-2307, 2012.
22. Bravo-Cordero JJ, Hodgson L and Condeelis J: Directed cell invasion and migration during metastasis. Curr Opin Cell Biol 24: 277-283, 2012.

23. Khan $\mathrm{N}$ and Mukhtar $\mathrm{H}$ : Cancer and metastasis: Prevention and treatment by green tea. Cancer Metastasis Rev 29: 435-445, 2010.

24. Wu ZY, Lien JC, Huang YP, Liao CL, Lin JJ, Fan MJ, Ko YC, Hsiao YP, Lu HF and Chung JG: Casticin inhibits A375.S2 human melanoma cell migration/invasion through downregulating $\mathrm{NF}-\kappa \mathrm{B}$ and matrix metalloproteinase-2 and -1 . Molecules 21: 384, 2016.

25. Guo Y, Hu B, Huang H, Tsung A, Gaikwad NW, Xu M, Jiang M, Ren S, Fan J, Billiar TR, et al: Estrogen sulfotransferase is an oxidative stress responsive gene that gender-specifically affects liver ischemia/reperfusion injury. J Biol Chem 290: 14754-14764, 2015.

26. Kobayashi EH, Suzuki T, Funayama R, Nagashima T, Hayashi M, Sekine H, Tanaka N, Moriguchi T, Motohashi H, Nakayama K and Yamamoto M: Nrf2 suppresses macrophage inflammatory response by blocking proinflammatory cytokine transcription. Nat Commun 7: 11624, 2016.

27. Geismann C, Arlt A, Sebens S and Schäfer H: Cytoprotection 'gone astray': Nrf2 and its role in cancer. Onco Targets Ther 7: 1497-1518, 2014.

28. Hayes JD and McMahon M: NRF2 and KEAP1 mutations: Permanent activation of an adaptive response in cancer. Trends Biochem Sci 34: 176-188, 2009.

29. Ferrándiz ML, Nacher-Juan J and Alcaraz MJ: Nrf2 as a therapeutic target for rheumatic diseases. Biochem Pharmacol 13: 338-346, 2018

30. Tsukimoto M, Tamaishi N, Homma T and Kojima S: Low-dose gamma-ray irradiation induces translocation of Nrf2 into nuclear in mouse macrophage RAW264.7 cells. J Radiat Res 51: 349-353, 2010.

31. Meng D, Wang X, Chang Q, Hitron A, Zhang Z, Xu M, Chen G, Luo J, Jiang B, Fang J and Shi X: Arsenic promotes angiogenesis in vitro via a heme oxygenase-1-dependent mechanism. Toxicol Appl Pharmacol 244: 291-299, 2010.

32. Pan H, Wang H, Zhu L, Mao L, Qiao L and Su X: The role of Nrf2 in migration and invasion of human glioma cell U251. World Neurosurg 80: 363-370, 2013.

33. Menegon S, Columbano A and Giordano S: The dual roles of NRF2 in cancer. Trends Mol Med 22: 578-593, 2016. 